\title{
MEDICINE
}

\section{CORRELATIONS BETWEEN LINEAR DIMENSIONS OF THE LUMBAR INTERVERTEBRAL DISCS AND SOMATOMETRIC PARAMETERS IN GIRLS AND IN WOMEN OF THE FIRST ADULTHOOD}

\author{
Danylevych V.P., \\ Assistant Professor, Ukraine, Vinnitsa, National Pirogov Memorial Medical University ORCID ID: \\ https://orcid.org/0000-0002-8074-6130
}

Guminskyi Y. Y., D.M., Professor, Ukraine, Vinnitsa, National Pirogov Memorial Medical University ORCID ID: https://orcid.org/0000-0002-8688-9829

Hryhorieva O. A., D.M., Professor, Ukraine, Zaporizzhya, Zaporizzhya State Medical University ORCID ID: https://orcid.org/0000-0002-6101-8322

DOI: https://doi.org/10.31435/rsglobal_ws/31052020/7075

\section{ARTICLE INFO}

Received: 16 March 2020

Accepted: 03 May 2020

Published: 31 May 2020

\section{KEYWORDS}

lumbar intervertebral discs, somatometry,

MRI,

correlation coefficient.

\begin{abstract}
The relationships between linear dimensions of the lumbar intervertebral discs $\left(I_{V D} 1-\mathrm{L} 2, \mathrm{IVD}_{\mathrm{L} 2-\mathrm{L} 3}, \mathrm{IVD}_{\mathrm{L} 3-\mathrm{L} 4}, \mathrm{IVD}_{\mathrm{L} 4-\mathrm{L} 5}\right)$ and somatometric parameters in girls and females of the first adulthood were investigated. The numerous relationships between the partial (height, sagittal and transverse sizes) linear dimensions and total sizes of the lumbar intervertebral discs in girls and women of the first adulthood (16-26 years) with their somatometric parameters were found. The linear dimensions of the lumbar intervertebral discs (height, sagittal and transverse sizes) were measured on the MRI images in the axial, sagittal and coronal plains. The arithmetic means of absolute correlation coefficients between particular and total individual sizes of $\operatorname{IVD}_{\mathrm{L} 1-\mathrm{L} 2}$, $I_{V D} D_{2-L 3}, \quad I V D_{L 3-L 4}, \quad I V D_{L 4-L 5}$ and relative quantity with somatometric parameters were calculated with following results: arithmetic means of absolute correlation coefficients for particular individual sizes are within $0,120-0,170$; for total sizes $-0,190$; for ratio of the total sizes to the mass-growth coefficient $-0,507$.
\end{abstract}

Citation: Danylevych V. P., Guminskyi Y. Y., Hryhorieva O. A. (2020) Correlations Between Linear Dimensions of the Lumbar Intervertebral Discs and Somatometric Parameters in Girls and in Women of the First Adulthood. World Science. 5(57), Vol.2. doi: 10.31435/rsglobal_ws/31052020/7075

Copyright: (C) 2020 Danylevych V. P., Guminskyi Y. Y., Hryhorieva O. A. This is an open-access article distributed under the terms of the Creative Commons Attribution License (CC BY). The use, distribution or reproduction in other forums is permitted, provided the original author(s) or licensor are credited and that the original publication in this journal is cited, in accordance with accepted academic practice. No use, distribution or reproduction is permitted which does not comply with these terms.

Introduction. The use of the noninvasive analysis of morphological properties, normative absolute and relative linear intervertebral discs dimensions for interpretation of the radiological results can improve the evidentiary direction of preclinical spine pathology manifestations definition, facilitate differential diagnosis, dynamic clinical observation and treatment effectiveness $[4,6,10]$. The constitutional and anatomical variations, the spondylometric parameters particularity of the functional spinal unit elements form an important prerequisites of spine pathology origin [7]. The obtained results of interrelations between linear IVDs sizes with somatometric parameters for detection of spine pathology 
are used. Nowadays one can find numerous studies concerning this scientific problem. However, researching correlations between partial linear dimensions and total sizes of IVDs with somatometric parameters of girls and women of the first adult age in Ukrainian studies are underrepresented.

The aim of research is to investigate the peculiarities of relationships between partial linear dimensions of the lumbar intervertebral discs $\left(I_{V D} D_{\text {L1-L2 }}, I_{V} D_{L 2-L 3}, I V D_{L 3-L 4}, I_{V D} D_{\text {4-L5 }}\right)$ and their total sizes with somatometric parameters in girls and females of the first adulthood.

Materials and methods. The Bioethics Committee of the National Pirogov Memorial Medical University (Vinnytsya) didn't find in research materials anything contrary basic bioethical norms of the Helsinki Declaration, the Council of Europe Convention on Human Rights and Biomedicine (1977), the relevant provisions of the WHO and the laws of Ukraine.

Individual somatometric investigation was performed for each person. General (body length and body weight) and particular sizes (the longitudinal, the transverse and the circumference sizes, pelvic sizes and skinfolds thickness) according to the V. Bunak procedure were measured [1]. The bony, muscle and fat components of the body mass were estimated by the method of Matiegka J. [8] and the American Institute of Nutrition (AIN) [9]. The lumbar spine MRI in girls and women of the first adulthood (16-26 years) with the measuring of anterior-posterior diameter, frontal diameter and vertical size of the lumbar IVD was carried out. The anterior height, medial height and posterior height of the IVDs in sagittal plane of MRI of the lumbar spine data were measured. Average height (height) of each lumbar IVDs was calculated as an arithmetic mean of the IVDs height in front, central and back portions on midsagittal plane of lumbar MRI data [3,5]. The total IVD size of investigated girls and women of the first adulthood was calculated as a sum of anterior-posterior diameter, frontal diameter and vertical size for each lumbar IVD. The statistic analysis was performed by using the Pearson's correlation coefficient (r) in the licensed statistical software «Statistica for Windows 13» (StatSoft Inc., № JPZ804I382130ARCN10-J). To assess the strength of the correlation, the Robert Chaddock system [2] was used.

Research results and discussion. It is established, that average height $\mathrm{IVD}_{\mathrm{L} 1-\mathrm{L} 2}$ has weak positive reliable Pearson's correlation coefficient ( $r$ ) with following somatometric measures: with component of the body mass $(\mathrm{r}=0,387, \mathrm{p}=0,001)$, with bony component of the body mass $(\mathrm{r}=0,308$, $\mathrm{p}=0,010)$, with muscle component of the body mass (AIN) $(\mathrm{r}=0,327, \mathrm{p}=0,006)$, arm circumference in tense condition $(\mathrm{r}=0,318, \mathrm{p}=0,007)$, forearm circumference in the lower third $(\mathrm{r}=0,323, \mathrm{p}=0,006)$, with thigh circumference $(\mathrm{r}=0,371, \mathrm{p}=0,002)$, with lower leg circumference $(\mathrm{r}=0,328, \mathrm{p}=0,006)$, with neck circumference $(\mathrm{r}=0,304, \mathrm{p}=0,010)$, with waist circumference $(\mathrm{r}=0,377, \mathrm{p}=0,001)$, with foot circumference $(r=0,400, p=0,001)$, with chest circumference at the state of full expiration $(r=0,331$, $\mathrm{p}=0,005)$, with chest circumference at the state of maximum inspiration $(\mathrm{r}=0,325, \mathrm{p}=0,006)$, with chest circumference at the state of mid expiration $(\mathrm{r}=0,337, \mathrm{p}=0,004)$.

The average height $\mathrm{IVD}_{\mathrm{L} 2-\mathrm{L} 3}$ has weak positive reliable Pearson's correlation coefficient ( $\mathrm{r}$ ) with muscle component of the body mass (AIN) $(\mathrm{r}=0,402, \mathrm{p}=0,001)$, with hand circumference $(\mathrm{r}=0,306, \mathrm{p}=0,010)$.

The average height $\mathrm{IVD}_{\mathrm{L} 3-\mathrm{L} 4}$ has weak positive reliable Pearson's correlation coefficient ( $\mathrm{r}$ ) with muscle component of the body mass (AIN) $(\mathrm{r}=0,395, \mathrm{p}=0,001)$, with anterior-posterior chest size $(\mathrm{r}=0,321, \mathrm{p}=0,007)$, with arm circumference in tense condition $(\mathrm{r}=0,467, \mathrm{p}=0,000)$, with arm circumference in calm condition $(\mathrm{r}=0,431, \mathrm{p}=0,000)$, with chest circumference at the state of full expiration $(r=0,447, p=0,000)$, with chest circumference at the state of maximum inspiration $(r=0,434$, $\mathrm{p}=0,000)$, with chest circumference at the state of mid expiration.

The average height IVD $_{\mathrm{L} 4-\mathrm{L} 5}$ has weak positive reliable Pearson's correlation coefficient ( $\mathrm{r}$ ) with muscle component of the body mass (AIN) $(\mathrm{r}=0,316, \mathrm{p}=0,008)$, with arm circumference in tense condition $(\mathrm{r}=0,394, \mathrm{p}=0,001)$, with arm circumference in calm condition $(\mathrm{r}=0,336, \mathrm{p}=0,004)$, with forearm circumference in the upper third $(\mathrm{r}=0,306, \mathrm{p}=0,010)$, with forearm circumference in the lower third $(r=0,327, p=0,006)$, with chest circumference at the state of full expiration $(r=0,356, p=0,002)$, with chest circumference at the state of maximum inspiration $(\mathrm{r}=0,371, \mathrm{p}=0,002)$, with chest circumference at the state of mid expiration $(\mathrm{r}=0,342, \mathrm{p}=0,004)$.

Total size IVD $\mathrm{L}_{\mathrm{L}-\mathrm{L} 2}$ has weak positive reliable Pearson's correlation coefficient (r) with body mass $(r=0,329, p=0,000)$, with body length $(r=0,332, p=0,000)$, with body surface area $(r=0,360$, $\mathrm{p}=0,000)$, with muscle component of the body mass (AIN) $(\mathrm{r}=0,327, \mathrm{p}=0,006)$, with suprasternal height $(r=0,323, p=0,006)$, with dactylon height $(r=0,319, p=0,007)$, with wrist breadth $(r=0,307$, 
$\mathrm{p}=0,010)$, with malleolus width $(\mathrm{r}=0,355, \mathrm{p}=0,003)$, with forearm circumference in the lower third $(\mathrm{r}=0,319, \mathrm{p}=0,007)$, with hand circumference $(\mathrm{r}=0,316, \mathrm{p}=0,008)$, with foot circumference $(\mathrm{r}=0,309$, $\mathrm{p}=0,009)$, with chest circumference at the state of full expiration $(\mathrm{r}=0,321, \mathrm{p}=0,007)$, with chest circumference at the state of mid expiration $(r=0,310, p=0,009)$.

Total size IVD $\mathrm{L} 2-\mathrm{L} 3_{3}$ has weak positive reliable Pearson's correlation coefficient $(\mathrm{r})$ with body surface area $(r=0,322, p=0,000)$, with muscle component of the body mass (AIN) $(r=0,312, p=0,009)$, with forearm circumference in the lower third $(r=0,323, p=0,006)$, with hand circumference $(r=0,309$, $\mathrm{p}=0,009)$, with chest circumference at the state of full expiration $(\mathrm{r}=0,361, \mathrm{p}=0,002)$, with chest circumference at the state of mid expiration $(\mathrm{r}=0,322, \mathrm{p}=0,007)$.

Total size IVD $\mathrm{L}_{\mathrm{L} 3-\mathrm{L} 4}$ has weak positive reliable Pearson's correlation coefficient $(\mathrm{r})$ with chest circumference at the state of full expiration $(\mathrm{r}=0,313, \mathrm{p}=0,008)$.

Total size IVD $\mathrm{L}_{\mathrm{L} 4-\mathrm{L} 5}$ has weak positive reliable Pearson's correlation coefficient $(\mathrm{r})$ with body surface area $(r=0,310, p=0,000)$, with muscle component of the body mass (AIN) $(r=0,301, p=0,009)$, with forearm circumference in the lower third $(\mathrm{r}=0,324, \mathrm{p}=0,006)$, with suprasternal height $(\mathrm{r}=0,301$, $\mathrm{p}=0,011)$, with chest circumference at the state of full expiration $(\mathrm{r}=0,328, \mathrm{p}=0,006)$, with chest circumference at the state of mid expiration $(\mathrm{r}=0,304, \mathrm{p}=0,011)$.

Ratio of the total sizes $\mathrm{IVD}_{\mathrm{L} 1-\mathrm{L} 2}$ to weight-length factor has weak negative reliable Pearson's correlation coefficient $(\mathrm{r})$ with following somatometric measures: with wrist width $(\mathrm{r}=-0,394$, $\mathrm{p}=0,001)$, with malleolus width $(\mathrm{r}=-0,338, \mathrm{p}=0,004$ with distancia spinarum $(\mathrm{r}=-0,330, \mathrm{p}=0,005)$, with distancia cristarum $(r=-0,433, p=0,000)$, with lower forearm circumference $(r=-0,490, p=0,000)$, with calf circumference $(\mathrm{r}=-0,487, \mathrm{p}=0,000)$, with hands circumference $(\mathrm{r}=-0,372, \mathrm{p}=0,002)$, with foot circumference $(\mathrm{r}=-0,402, \mathrm{p}=0,001)$, with anterior-posterior chest size $(\mathrm{r}=-0,461, \mathrm{p}=0,000)$; with triceps skinfold $(\mathrm{r}=-0,437, \mathrm{p}=0,000)$, with biceps skinfold $(\mathrm{r}=-0,330, \mathrm{p}=0,005)$, with subscapular skinfold $(\mathrm{r}=-0,492, \mathrm{p}=0,000)$, with abdominal skinfold $(\mathrm{r}=-0,472, \mathrm{p}=0,000)$, with endomorphic component $(\mathrm{r}=-0,480, \mathrm{p}=0,000)$.

Ratio of the total sizes IVD $_{\text {L1-L2 }}$ to weight-length factor has moderate negative reliable Pearson's correlation coefficient (r) with following somatometric measures: with elbow width $(\mathrm{r}=-0,558, \mathrm{p}=0,000)$, with transverse mid-sternal size $(\mathrm{r}=-0,551, \mathrm{p}=0,000)$, with transverse lowersternal size $(\mathrm{r}=-0,584, \mathrm{p}=0,000)$, with distal femur width $(\mathrm{r}=-0,558, \mathrm{p}=0,000)$, with distancia trochanterica $(r=-0,556, p=0,000)$, with suprailiac skinfold $(r=-0,501, p=0,000)$, with chest circumference (inspiration) $(\mathrm{r}=-0,672, \mathrm{p}=0,000)$, with chest circumference (full expiration) $(\mathrm{r}=-0,696$, $\mathrm{p}=0,000)$, with chest circumference (mid expiration) $(\mathrm{r}=-0,698, \mathrm{p}=0,000)$, with calf circumference $(r=-0,610, p=0,000)$, with neck circumference $(r=-0,597, p=0,000)$, with mesomorphic component $(\mathrm{r}=-0,626, \mathrm{p}=0,000)$.

Ratio of the total sizes IVD $_{\text {L1-L2 }}$ to weight-length factor has high positive reliable Pearson's correlation coefficient (r) with following somatometric measures: with ectomorphic component $(\mathrm{r}=0,820, \mathrm{p}=0,000)$ and high negative reliable Pearson's correlation coefficient $(\mathrm{r})$ with following somatometric measures: with body mass $(\mathrm{r}=-0,794, \mathrm{p}=0,000)$, with body surface area $(\mathrm{r}=-0,733$, $\mathrm{p}=0,000)$, with weight-length rate $(\mathrm{r}=-0,837, \mathrm{p}=0,000)$, with BMI $(\mathrm{r}=-0,843, \mathrm{p}=0,000)$, with conjugata externa $(r=-0,727, p=0,000)$; with tense arm circumference $(r=-0,761, p=0,000)$, with calm arm circumference $(r=-0,785, p=0,000)$, with upper forearm circumference $(r=-0,774, p=0,000)$, with thigh circumference $(r=-0,759, p=0,000)$, with waist circumference $(r=-0,740, p=0,000)$.

Ratio of the total sizes $\mathrm{IVD}_{\mathrm{L} 2-\mathrm{L} 3}$ to weight-length factor has weak negative reliable Pearson's correlation coefficient $(r)$ with following somatometric measures: with wrist width $(r=-0,411$, $\mathrm{p}=0,000)$, with malleolus width $(\mathrm{r}=-0,404, \mathrm{p}=0,001)$, with anterior-posterior chest size $(\mathrm{r}=-0,464$, $\mathrm{p}=0,000)$, with distancia spinarum $(\mathrm{r}=-0,362, \mathrm{p}=0,002)$, with distancia cristarum $(\mathrm{r}=-0,441, \mathrm{p}=0,000)$, with lower forearm circumference $(\mathrm{r}=-0,475, \mathrm{p}=0,000)$, with lower leg circumference $(\mathrm{r}=-0,495$, $\mathrm{p}=0,000)$, with hands circumference $(\mathrm{r}=-0,330, \mathrm{p}=0,005)$, with foot circumference $(\mathrm{r}=-0,421$, $\mathrm{p}=0,000)$, with triceps skinfold $(\mathrm{r}=-0,482, \mathrm{p}=0,000)$, with biceps skinfold $(\mathrm{r}=-0,365, \mathrm{p}=0,002)$, with calf skinfold $(r=-0,321, p=0,007)$, with abdominal skinfold $(r=-0,498, p=0,000)$.

Ratio of the total sizes $\mathrm{IVD}_{\mathrm{L} 2-\mathrm{L} 3}$ to weight-length factor has moderate negative reliable Pearson's correlation coefficient $(\mathrm{r})$ with following somatometric measures: with elbow width $(\mathrm{r}=-0,545, \mathrm{p}=0,000)$, with elbow width $(\mathrm{r}=-0,572, \mathrm{p}=0,000)$, with transverse mid-sternal size $(\mathrm{r}=-0,571$, $\mathrm{p}=0,000)$, with transverse lower-sternal size $(\mathrm{r}=-0,595, \mathrm{p}=0,000),(\mathrm{r}=-0,580, \mathrm{p}=0,000)$, with upper forearm circumference $(r=-0,674, p=0,000)$, with calf circumference $(r=-0,616, p=0,000)$, with neck 
circumference $(\mathrm{r}=-0,594, \mathrm{p}=0,000)$, with chest circumference (inspiration) $(\mathrm{r}=-0,630, \mathrm{p}=0,000)$, with chest circumference (full expiration) ( $\mathrm{r}=-0,679, \mathrm{p}=0,000)$, with chest circumference (mid expiration) $(\mathrm{r}=-0,671, \mathrm{p}=0,000)$; with subscapular skinfold $(\mathrm{r}=-0,524, \mathrm{p}=0,000)$, with suprailiac skinfold $(\mathrm{r}=-0,527, \mathrm{p}=0,000)$, with endomorphic component $(\mathrm{r}=-0,506, \mathrm{p}=0,000)$, with mesomorphic component $(\mathrm{r}=-0,593, \mathrm{p}=0,000)$, with muscle component of the body mass $(\mathrm{r}=-0,670, \mathrm{p}=0,000)$, with bony component of the body mass $(\mathrm{r}=-0,589, \mathrm{p}=0,000)$, with fat component of the body mass $(r=-0,548, p=0,000)$, with muscle component of the body mass (AIN) $(r=0,597, p=0,000)$;

Ratio of the total sizes $\mathrm{IVD}_{\mathrm{L} 2-\mathrm{L} 3}$ to weight-length factor has high positive reliable Pearson's correlation coefficient ( $\mathrm{r}$ ) with following somatometric measures: with ectomorphic component $(\mathrm{r}=0,795, \mathrm{p}=0,000)$ and high negative reliable Pearson's correlation coefficient $(\mathrm{r})$ with following somatometric measures: with body mass $(\mathrm{r}=-0,788, \mathrm{p}=0,000)$, with body surface area $(\mathrm{r}=-0,730$, $\mathrm{p}=0,000)$, with weight-length rate $(\mathrm{r}=-0,828, \mathrm{p}=0,000)$, with BMI $(\mathrm{r}=-0,831, \mathrm{p}=0,000)$, with conjugata externa $(r=-0,745, p=0,000)$, with arm circumference in tense condition $(r=-0,746, p=0,000)$, with arm circumference in calm condition $(\mathrm{r}=-0,773, \mathrm{p}=0,000)$, with waist circumference $(\mathrm{r}=-0,726, \mathrm{p}=0,000)$, with thigh circumference $(\mathrm{r}=-0,764, \mathrm{p}=0,000)$.

Ratio of the total sizes IVD $\mathrm{L}_{\mathrm{L}-\mathrm{L} 4}$ to weight-length factor has weak negative reliable Pearson's correlation coefficient $(r)$ with following somatometric measures: with wrist width $(\mathrm{r}=-0,398$, $\mathrm{p}=0,001)$, with malleolus width $(\mathrm{r}=-0,420, \mathrm{p}=0,001)$, with anterior-posterior chest size $(\mathrm{r}=-0,445$, $\mathrm{p}=0,000)$; with distancia spinarum $(\mathrm{r}=-0,321, \mathrm{p}=0,007)$, with distancia cristarum $(\mathrm{r}=-0,454, \mathrm{p}=0,000)$, with lower forearm circumference $(\mathrm{r}=-0,496, \mathrm{p}=0,000)$, with hands circumference $(\mathrm{r}=-0,378, \mathrm{p}=0,001)$, with foot circumference $(\mathrm{r}=-0,447, \mathrm{p}=0,000)$, with triceps skinfold $(\mathrm{r}=-0,476, \mathrm{p}=0,000)$, with biceps skinfold $(\mathrm{r}=-0,376, \mathrm{p}=0,001)$, with abdominal skinfold $(\mathrm{r}=-0,495, \mathrm{p}=0,000)$, with calf skinfold $(r=-0,313, p=0,008)$, with endomorphic component $(r=-0,496, p=0,000)$.

Ratio of the total sizes $\mathrm{IVD}_{\mathrm{L} 3-\mathrm{L} 4}$ to weight-length factor has moderate negative reliable Pearson's correlation coefficient $(r)$ with following somatometric measures: with elbow width $(\mathrm{r}=-0,525, \mathrm{p}=0,000)$, with distal femur width $(\mathrm{r}=-0,598, \mathrm{p}=0,000)$, with transverse mid-sternal size $(\mathrm{r}=-0,536, \mathrm{p}=0,000)$, with transverse lower-sternal size $(\mathrm{r}=-0,556, \mathrm{p}=0,000)$, with distancia trochanterica $(r=-0,597, p=0,000)$, with upper forearm circumference $(r=-0,666, p=0,000)$, with calf circumference $(r=-0,609, p=0,000)$, with lower leg circumference $(r=-0,517, p=0,000)$, with neck circumference $(r=-0,602, p=0,000)$, with chest circumference (inspiration) $(r=-0,652, p=0,000)$, with chest circumference (full expiration) $(\mathrm{r}=-0,684, \mathrm{p}=0,000)$, with chest circumference (mid expiration) $(\mathrm{r}=-0,683, \mathrm{p}=0,000)$; with subscapular skinfold $(\mathrm{r}=-0,509, \mathrm{p}=0,000)$, with suprailiac skinfold $(r=-0,525, p=0,000)$, with mesomorphic component $(r=-0,578, p=0,000)$, with muscle component of the body mass $(r=-0,684, p=0,000)$, with bony component of the body mass $(r=-0,599, p=0,000)$, with fat component of the body mass $(\mathrm{r}=-0,555, \mathrm{p}=0,000)$, with muscle component of the body mass (AIN) $(\mathrm{r}=0,598, \mathrm{p}=0,000)$.

Ratio of the total sizes IVD $_{\mathrm{L} 3-\mathrm{L} 4}$ to weight-length factor has high positive reliable Pearson's correlation coefficient (r) with following somatometric measures: with ectomorphic component $(\mathrm{r}=0,815, \mathrm{p}=0,000)$ and high negative reliable Pearson's correlation coefficient $(\mathrm{r})$ with following somatometric measures: with body mass $(\mathrm{r}=-0,809, \mathrm{p}=0,000)$, with body surface area $(\mathrm{r}=-0,750$, $\mathrm{p}=0,000)$, with weight-length rate $(\mathrm{r}=-0,845, \mathrm{p}=0,000)$, with BMI $(\mathrm{r}=-0,846, \mathrm{p}=0,000)$, with conjugata externa $(r=-0,756, p=0,000)$, with thigh circumference $(r=-0,788, p=0,000)$, with tense arm circumference $(r=-0,751, p=0,000)$, with calm arm circumference $(r=-0,787, p=0,000)$, with waist circumference $(\mathrm{r}=-0,739, \mathrm{p}=0,000)$.

Ratio of the total sizes IVD $\mathrm{L}_{\mathrm{L}-\mathrm{L} 5}$ to weight-length factor has weak negative reliable Pearson's correlation coefficient $(r)$ with following somatometric measures: with wrist width $(\mathrm{r}=-0,440$, $\mathrm{p}=0,000)$, with distal femur width $(\mathrm{r}=-0,430, \mathrm{p}=0,000)$, with anterior-posterior chest size $(\mathrm{r}=-0,482$, $\mathrm{p}=0,000)$, with distancia spinarum $(\mathrm{r}=-0,306, \mathrm{p}=0,001)$, with distancia cristarum $(\mathrm{r}=-0,418, \mathrm{p}=0,000)$, with lower forearm circumference $(\mathrm{r}=-0,495, \mathrm{p}=0,000)$, with foot circumference $(\mathrm{r}=-0,474, \mathrm{R}=-0,488$ $\mathrm{p}=0,000)$, with hands circumference $(\mathrm{r}=-0,397, \mathrm{p}=0,001)$, with triceps skinfold $(\mathrm{r}=-0,440, \mathrm{p}=0,000)$, with biceps skinfold $(\mathrm{r}=-0,354, \mathrm{p}=0,003)$, ), with abdominal skinfold $(\mathrm{r}=-0,476, \mathrm{p}=0,000)$, with calf skinfold $(r=-0,305, p=0,010)$, with endomorphic component $(r=-0,495, p=0,000)$.

Ratio of the total sizes $\mathrm{IVD}_{\mathrm{L} 4-\mathrm{L} 5}$ to weight-length factor has moderate negative reliable Pearson's correlation coefficient $(r)$ with following somatometric measures: with elbow width $(\mathrm{r}=-0,556, \mathrm{p}=0,000)$, with distal femur width $(\mathrm{r}=-0,596, \mathrm{p}=0,000)$, with transverse mid-sternal size 
$(\mathrm{r}=-0,551, \mathrm{p}=0,000)$, with transverse lower-sternal size $(\mathrm{r}=-0,546, \mathrm{p}=0,000)$, with distancia trochanterica $(r=-0,569, p=0,000)$, with upper forearm circumference $(r=-0,674, p=0,000)$, with calf circumference $(r=-0,644, p=0,000)$, with lower leg circumference $(r=-0,576, p=0,000)$, with neck circumference $(\mathrm{r}=-0,578, \mathrm{p}=0,000)$, with chest circumference (inspiration) $(\mathrm{r}=-0,677, \mathrm{p}=0,000)$, with subscapular skinfold $(\mathrm{r}=-0,515, \mathrm{p}=0,000$ with suprailiac skinfold $(\mathrm{r}=-0,506, \mathrm{p}=0,000)$, with mesomorphic component $(\mathrm{r}=-0,612, \mathrm{p}=0,000)$, with muscle component of the body mass $(\mathrm{r}=-0,694$, $\mathrm{p}=0,000)$, with bony component of the body mass $(\mathrm{r}=-0,611, \mathrm{p}=0,000)$, with fat component of the body mass $(r=-0,546, p=0,000)$, with muscle component of the body mass (AIN) $(r=0,620, p=0,000)$.

Ratio of the total sizes IVD $_{\mathrm{L} 4-\mathrm{L} 5}$ to weight-length factor has high positive reliable Pearson's correlation coefficient $(\mathrm{r})$ with following somatometric measures: with ectomorphic component $(\mathrm{r}=0,839, \mathrm{p}=0,000)$ and high negative reliable Pearson's correlation coefficient $(\mathrm{r})$ with following somatometric measures: with body mass $(\mathrm{r}=-0,821, \mathrm{p}=0,000)$, with body surface area $(\mathrm{r}=-0,762$, $\mathrm{p}=0,000)$, with weight-length rate $(\mathrm{r}=-0,860, \mathrm{p}=0,000)$, with $\mathrm{BMI}(\mathrm{r}=-0,861, \mathrm{p}=0,000)$, with conjugata externa $(\mathrm{r}=-0,747, \mathrm{p}=0,000)$, with arm circumference in tense condition $(\mathrm{r}=-0,765, \mathrm{p}=0,000)$, with arm circumference in calm condition $(r=-0,787, p=0,000)$, with thigh circumference $(r=-0,793, p=0,000)$, with waist circumference $(\mathrm{r}=-0,738, \mathrm{p}=0,000)$, with chest circumference (full expiration) ( $\mathrm{r}=-0,707$, $\mathrm{p}=0,000)$, with chest circumference (mid expiration) $(\mathrm{r}=-0,709, \mathrm{p}=0,000)$.

Qualitative assessment of the relationships between partial sizes, total sizes and ratios of the total sizes $\mathrm{IVD}_{\mathrm{L} 4-\mathrm{L} 5}$ to weight-length factor with somatometric parameters were performed by calculating of the arithmetic means of absolute correlation coefficients between particular sizes, total sizes of IVD $\mathrm{L}_{\mathrm{L} 1-\mathrm{L} 2}, \mathrm{IVD}_{\mathrm{L} 2-\mathrm{L} 3}, \mathrm{IVD}_{\mathrm{L} 3-\mathrm{L} 4}, \mathrm{IVD}_{\mathrm{L} 4-\mathrm{L} 5}$ and relative quantities with somatometric parameters.

The calculated arithmetic means of absolute correlation coefficients between particular sizes, total sizes of $\mathrm{IVD}_{\mathrm{L} 1-\mathrm{L} 2}, \mathrm{IVD}_{\mathrm{L} 2-\mathrm{L} 3}, \mathrm{IVD}_{\mathrm{L} 3-\mathrm{L} 4}, \mathrm{IVD}_{\mathrm{L} 4-\mathrm{L} 5}$ and relative quantities with somatometric parameters in girls and women of the first adulthood (16-26 years) are represented in the table 1.

Table 1. The arithmetic means of absolute correlation coefficients between particular sizes, total sizes of $\mathrm{IVD}_{\mathrm{L} 1-\mathrm{L} 2}, \mathrm{IVD}_{\mathrm{L} 2-\mathrm{L} 3}, \mathrm{IVD}_{\mathrm{L} 3-\mathrm{L} 4}, \mathrm{IVD}_{\mathrm{L} 4-\mathrm{L} 5}$ and relative quantities with somatometric parameters in girls and women of the first adulthood (16-26 years)

\begin{tabular}{|c|c|}
\hline Parameters & $\begin{array}{l}\text { The arithmetic means of absolute } \\
\text { correlation coefficients }\end{array}$ \\
\hline Transverse size $\mathrm{IVD}_{\mathrm{L} 1-\mathrm{L} 2}, \mathrm{~mm}$ & 0,149 \\
\hline Transverse size IVD $\mathrm{L} 2-\mathrm{L} 3_{3}, \mathrm{~mm}$ & 0,148 \\
\hline Transverse size $\mathrm{IVD}_{\mathrm{L} 3-\mathrm{L} 4}, \mathrm{~mm}$ & 0,076 \\
\hline Transverse size IVD $\mathrm{L}_{\mathrm{L}-\mathrm{L} 5}, \mathrm{~mm}$ & $\mathbf{0 , 1 2 3}$ \\
\hline Sagittal size IVD $\mathrm{L}_{\mathrm{L} 1-\mathrm{L} 2}, \mathrm{~mm}$ & $\mathbf{0 , 1 3 9}$ \\
\hline Sagittal size $\mathrm{IVD}_{\mathrm{L} 2-\mathrm{L} 3}, \mathrm{~mm}$ & $\mathbf{0 , 1 4 0}$ \\
\hline Sagittal size $\mathrm{IVD}_{\mathrm{L} 3-\mathrm{L} 4}, \mathrm{~mm}$ & 0,149 \\
\hline Sagittal size IVD $\mathrm{L}_{\mathrm{L} 4-\mathrm{L} 5}, \mathrm{~mm}$ & $\mathbf{0 , 1 4 1}$ \\
\hline Average height IVD $\mathrm{L} 1-\mathrm{L} 2, \mathrm{~mm}$ & 0,198 \\
\hline Average height IVD $\mathrm{L} 2-\mathrm{L} 3_{3}, \mathrm{~mm}$ & $\mathbf{0 , 1 0 2}$ \\
\hline Average height $\mathrm{IVD}_{\mathrm{L} 3-\mathrm{L} 4}, \mathrm{~mm}$ & 0,204 \\
\hline Average height IVD $\mathrm{L} 4-\mathrm{L} 5_{5}, \mathrm{~mm}$ & $\mathbf{0 , 1 7 7}$ \\
\hline Total size IVD $\mathrm{L}_{\mathrm{L} 1-\mathrm{L} 2}, \mathrm{~mm}$ & 0,216 \\
\hline Total size $\mathrm{IVD}_{\mathrm{L} 2-\mathrm{L} 3}, \mathrm{~mm}$ & $\mathbf{0 , 1 8 1}$ \\
\hline Total size IVD $\mathrm{L}_{\mathrm{L}-\mathrm{L} 4}, \mathrm{~mm}$ & 0,161 \\
\hline Total size $\mathrm{IVD}_{\mathrm{L} 4-\mathrm{L} 5}, \mathrm{~mm}$ & $\mathbf{0 , 1 8 8}$ \\
\hline Ratio of the total sizes IVD $\mathrm{L}$ 1-L2 $_{\text {to }}$ weight-length factor & 0,495 \\
\hline Ratio of the total sizes IVD $\mathrm{L}_{\mathrm{L} 2 \mathrm{~L} 3}$ to weight-length factor & 0,506 \\
\hline Ratio of the total sizes IVD $\mathrm{L}_{\mathrm{L}-\mathrm{L} 4}$ to weight-length factor & $\mathbf{0 , 5 1 0}$ \\
\hline Ratio of the total sizes IVD $\mathrm{L}_{\text {L-L5 }}$ to weight-length factor & 0,515 \\
\hline
\end{tabular}


Conclusions. The arithmetic means of absolute correlation coefficients between particular

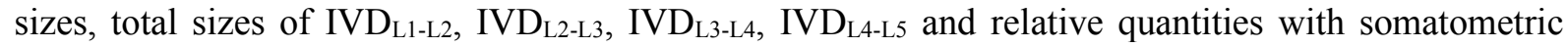
parameters in girls and women of the first adulthood (16-26 years) in general is for

- transverse sizes - 0,120;

- sagittal sizes - 0,140;

- average heights $-0,170$

- total sizes - 0,190;

- ratio of the total sizes IVDs to weight-length factor $-0,507$.

Analysis of the arithmetic means of absolute correlation coefficients between particular sizes, total sizes of $\mathrm{IVD}_{\mathrm{L} 1-\mathrm{L} 2}, \mathrm{IVD}_{\mathrm{L} 2-\mathrm{L} 3}, \mathrm{IVD}_{\mathrm{L} 3-\mathrm{L} 4}, \mathrm{IVD}_{\mathrm{L} 4-\mathrm{L} 5}$ and relative quantities with somatometric parameters in girls and women of the first adulthood (16-26 years) represented their gradual raising. Therefore, the arithmetic means of absolute correlation coefficients between particular sizes (height, sagittal and transverse sizes of IVDs) with somatometric parameters were from 0,120 to 0,170 ; at the same time coefficient for total sizes become 0,190 . The using of ratios of the total sizes IVDs to weight-length factors led to increasing arithmetic means of absolute correlation coefficients with somatometric parameters to 0,507 . The studying of interrelations between somatometric parameters with spondylometric dimensions of the lumbar, thoracic and cervical functional spinal units is a perspective one and can be used for the development of the further mathematical modeling to individualize prediction and early detection of pathological changes of the spinal motor segments.

\section{REFERENCES}

1. Bunak, V. V. (1941). Anthropometry: a practical course. M.: Uchpedgiz.

2. Chaddock R.E. (1925). Principles and methods of statistics (Houghton Mifflin Co.; 1st edition). https://doi.org/10.1177/000271622612300150

3. Danylevych, V., Guminskyi, Y., Tykholaz, V., Bezsmertnyi, Y., Pavlov, S., \& Bezsmertna, H. (2019). Mathematical modeling of individual parameters of the sum of the sizes intervertebral discs of the lumbar spine in juvenile males and males of the first mature age in norm. Reports of Morphology, 25(1), 68-76. https://doi.org/10.31393/morphology-journal-2019-25(1)-109

4. Fallah, F., Walter, S. S., Bamberg, F., \& Yang, B. (2019). Simultaneous Volumetric Segmentation of Vertebral Bodies and Intervertebral Discs on Fat-Water MR Images. IEEE Journal of Biomedical and Health Informatics, 23(4), 1692-1701. https://doi.org/10.1109/JBHI.2018.2872810

5. Guminsky, Y. Y. (2001). Proportionality in somato-visceral interrelations humans' body in norm. Reports of Morphology, 3(2), 319-323. 8

6. Hwang, D., Kim, S., Abeydeera, N.A. (2016). Quantitative magnetic resonance imaging of the lumbar intervertebral discs. Quant Imaging Med Surg. 6, 744-755. doi: 10.21037/qims.2016.12.09

7. Maeda, T., Hashizume, H., Yoshimura, N. (2018). Factors associated with lumbar spinal stenosis in a largescale, population-based cohort: The Wakayama Spine Study. PLoS One. 2018;13(7):e0200208. Published 2018 Jul 18. https://doi.org/10.1371/journal.pone.0200208

8. Matiegka, J. (1921). The testing of physical effeciecy. Amer. J. Phys. Antropol., 2(3), 25-38. https://doi.org/10.1002/ajpa.1330040302

9. Shephard, R. J. (2005). Body composition in biological anthropology. Cambridge University Press, Cambridge, UK; New York. Retrieved from https://trove.nla.gov.au/version/27821869 7

10. Zheng, G., Chu, C., Belavý, D.L. (2107) Evaluation and comparison of 3D intervertebral disc localization and segmentation methods for 3D T2 MR data: a grand challenge. Med Image Anal. 35, 327-344. https://doi.org/10.1016/j.media.2016.08.005 